\title{
ANÁLISE DE ESTRATÉGIAS PEDAGÓGICAS SOBRE O TEMA “ÁGUA” APLICADAS EM UMA ESCOLA DO CAMPO DE UBERLÂNDIA- MINAS GERAIS
}

Ingrid da Silva Pacheco - ingrid_1194@ hotmail.com

LAETE- Laboratório de Armazenamento de Energia e Tratamento de Efluentes Universidade Federal de Uberlândia - UFU

Maraína Souza Medeiros - maraliss@ hotmail.com

LAETE- Laboratório de Armazenamento de Energia e Tratamento de Efluentes Universidade Federal de Uberlândia - UFU

Layla Giovanna Girotto - laylagg.eab@gmail.com

LAETE- Laboratório de Armazenamento de Energia e Tratamento de Efluentes Universidade Federal de Uberlândia - UFU

Edyane Tássia Padilha - edyanetassia@hotmail.com

Universidade Federal de Uberlândia - UFU

LAETE- Laboratório de Armazenamento de Energia e Tratamento de Efluentes

Felipe Eduardo Sousa Oliveira - felipeeduardo@ufu.br

LAETE- Laboratório de Armazenamento de Energia e Tratamento de Efluentes

Universidade Federal de Uberlândia - UFU

Sheila Cristina Canobre - scanobre@ yahoo.com.br

LAETE- Laboratório de Armazenamento de Energia e Tratamento de Efluentes

Universidade Federal de Uberlândia - UFU

Fábio Augusto do Amaral - fabioamaral@ yahoo.com.br

LAETE- Laboratório de Armazenamento de Energia e Tratamento de Efluentes Universidade Federal de Uberlândia - UFU 


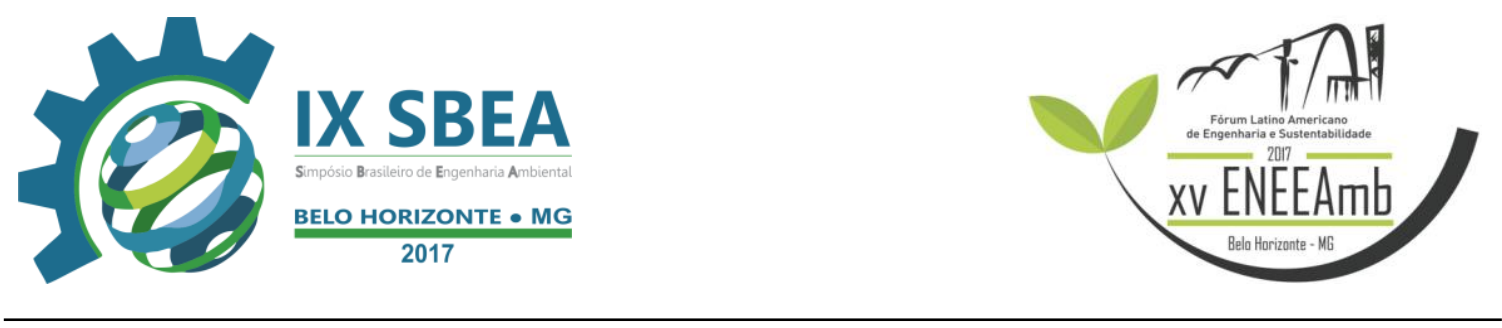

\section{RESUMO}

Com o intuito de promover a conscientização de discentes do Ensino Fundamental de uma Escola do Campo, em relação aos recursos hídricos, o presente estudo buscou realizar e avaliar ações de Educação Ambiental (EA) com as turmas de $5^{\circ}$ e $9^{\circ}$ anos. As aulas foram ministradas por graduandos de Engenharia Ambiental da UFU (educadores ambientais), sendo utilizadas estratégias pedagógicas motivadoras e adaptadas conforme a idade escolar do público alvo. Como resultados destaca-se a agregação de novos conhecimentos relacionados à crise hídrica, melhor conscientização de atitudes que visam economia da água e maior participação pelos alunos do $5^{\circ}$ ano. No entanto, destacam-se as dificuldades de diferenciação dos termos "poluição" e "contaminação" pelos alunos de ambas as turmas, necessitando de uma nova abordagem em atividades futuras. Ademais, destaca-se que a estratégia com maior grau de satisfação por ambas às turmas foi o vídeo educativo.

Palavras-chave: Estratégias pedagógicas, Recursos hídricos, Análise de satisfação.

\section{INTRODUÇÃO/OBJETIVO}

Nos últimos anos, pesquisadores tem mencionado a crescente degradação dos corpos d'água em função de ações antrópicas, promovendo a necessidade da realização de ações emergentes que visam à recuperação, conservação e preservação destes recursos (WESENDONCK; PRADO, 2015).

Neste contexto, um dos possíveis caminhos para se alcançar mudanças comportamentais dos indivíduos é através de Programas de Educação Ambiental (EA) voltados para o debate dos problemas de degradação de ambientes aquáticos (FERREIRA, 2015). Sendo que, surgiram várias discussões em todo o mundo sobre a EA em eventos de cunho social e político, gerando ferramentas que visam combater a crise ambiental que assola o planeta terra, bem como o posicionamento de ambientalistas acerca dessa situação (FREITAS; MARIN, 2015). Nesse sentido, a EA inserida no Ensino Fundamental torna-se essencial para propor práticas relacionadas à sustentabilidade nesta etapa de escolarização, despertando e construindo uma nova forma de pensar e agir dos 


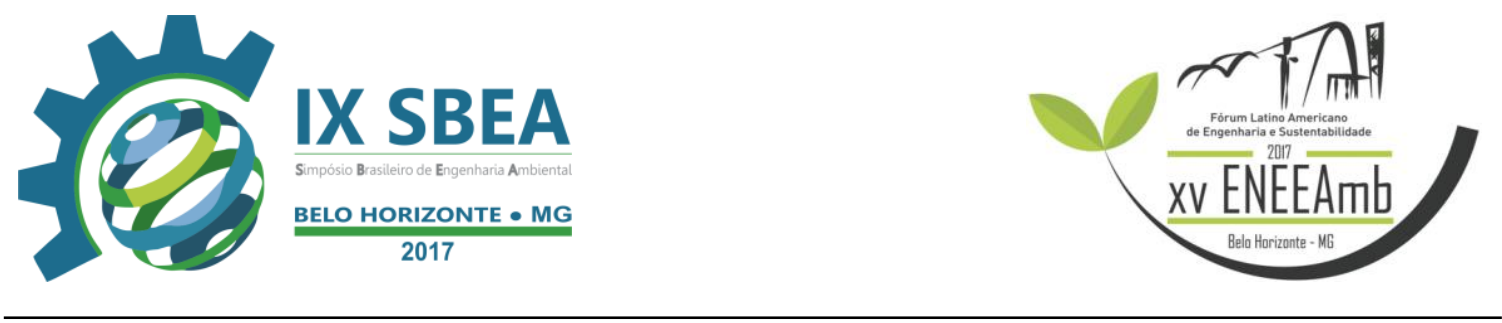

alunos frente à problemática da qualidade da água na zona rural, assim como da disponibilidade desse recurso para fins de consumo humano (MASSABNI et al., 2015).

Conduzido por esta perspectiva, este estudo teve por objetivo analisar a eficiência de estratégias pedagógicas adotadas em aulas de EA (jogos educativos, vídeos, experimentos práticos, e apresentação de projeções de slides), na construção da percepção ambiental e do conhecimento sobre os recursos hídricos pelos discentes do $5^{\circ}$ e $9^{\circ}$ anos, de uma Escola do Campo de Uberlândia, Minas Gerais. Ademais, adotou-se o termo "Escola do Campo" para preservar os direitos individuais da instituição analisada.

\section{METODOLOGIA}

As estratégias pedagógicas adotadas neste trabalho foram aplicadas por educadores ambientais (graduandos em Engenharia Ambiental da UFU) nas turmas do $5^{\circ}$ e $9^{\circ}$ anos de uma Escola do Campo de Uberlândia-MG. As aulas foram expositivas, dialogadas e interativas, utilizando-se como ferramentas materiais escolares, laboratoriais e recursos audiovisuais. A exposição do conteúdo foi estruturada em quatro partes, sendo articulados e definidos pelos educadores ambientais, conforme pode ser visto na Figura 1.

Figura 1 - Fluxograma representando os temas trabalhados durante as aulas ministradas aos alunos do $5^{\circ}$ e $9^{\circ}$ anos na Escola do Campo de Uberlândia-MG.

\begin{tabular}{|c|c|c|c|}
\hline Parte 1 & Parte 2 & Parte 3 & Parte 4 \\
\hline $\begin{array}{l}\text { •A água e o } \\
\text { meio ambiente } \\
\text { •Video "O Uso } \\
\text { racional da } \\
\text { água" }\end{array}$ & $\begin{array}{c}\text { • Jogo } \\
\text { Educativo } \\
\text { sobre a água } \\
\text { •Questão } \\
\text { dissertativa }\end{array}$ & $\begin{array}{c}\text {-Experimento } \\
\text { prático } \\
\text { sensorial } \\
\text { sobre as } \\
\text { caracterísicas } \\
\text { da água }\end{array}$ & $\begin{array}{l}\text { •Entrega de } \\
\text { lembrancinhas } \\
\text { • Aplicação do } \\
\text { questionário } \\
\text { de satisfação }\end{array}$ \\
\hline
\end{tabular}

Parte 1 - A água e o meio ambiente: Tratou-se de uma abordagem expositiva e dialogada dos temas da aula, por meio de apresentação de slides: (a) Importância da água; (b) Desperdício em atividades cotidianas; (c) Contaminação e poluição; e (d) Doenças de veiculação hídrica. Em seguida, mostrou-se aos alunos um vídeo educativo, fornecido e 
divulgado na internet pela Agência Nacional das Águas (ANA), com duração de 5 minutos, e intitulado "O uso racional da água”.

Parte 2 - Jogo educativo sobre a água: O jogo elaborado pelos educadores ambientais deste trabalho é composto de seis perguntas de múltipla escolha e uma dissertativa. Os alunos tinham cerca de um minuto para marcar a alternativa mais adequada e três minutos para elaboração da resposta discursiva. Logo, este módulo prioriza o raciocínio rápido e aprofundamento da teoria apresentada na Parte 1.

Parte 3 - Experimento prático sensorial das características da água: consistia em verificar as características da água (incolor, insípida e inodora) a partir de um experimento com três erlenmeyers contendo três tipos de água em cada frasco ( $1^{\text {a }}$ : água limpa do bebedouro; $2^{\mathrm{a}}$ : água com gotas de vinagre (ácido acético); e $3^{\mathrm{a}}$ : água com sedimentos de terra). O educador ambiental questionou a turma sobre qual ou quais das três águas contidas nos frascos não seriam próprias para consumo humano. Com base nas respostas, foram explicadas as três características fundamentais da água e ressaltou-se a importância de se consumir água com boa qualidade.

Parte 4-Lembrancinhas e questionários: Para finalizar a aula, foi entregue aos alunos uma lembrancinha educativa (gotinha d'água com um pirulito) contendo a seguinte frase: "Economize água! Faça um uso consciente! As futuras gerações agradecem" para reforçar positivamente todos os conhecimentos adquiridos em aula. Por fim, aplicou-se um questionário de satisfação com os alunos das turmas com o intuito de verificar a opinião dos mesmos em relação a cada tipo de atividade que foi desenvolvida durante a aula, e assim verificar a eficácia da metodologia adotada.

\section{RESULTADOS E DISCUSSÃO}

$\mathrm{Na}$ aula ministrada ao $9^{\circ}$ ano, sobre os questionamentos iniciais, notou-se que os alunos possuíam conhecimento sobre os assuntos relacionados à água, como sua importância, as formas de economizá-la, e o significado de "escassez". No entanto, os alunos se mostraram dispersos, sem interesse e resistentes a interagir e responder os questionamentos realizados. Este fato pode estar relacionado à aula ter sido aplicada no ultimo horário, assim os alunos já estavam exaustos e com desejo de ir embora. Além disso, ressalta-se que como o conteúdo e o plano de aula foram o mesmo que o 


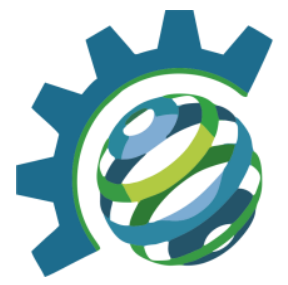

apresentado ao $5^{\circ}$ ano supõe-se que os alunos acharam simples e fácil, influenciando na dificuldade de prender a atenção dos mesmos.

$\mathrm{Na}$ aula desenvolvida separadamente no $5^{\circ}$ ano (17 alunos) e $9^{\circ}$ ano (13 alunos) na Escola do Campo analisada, em relação à aplicação do jogo educativo, os educandos obtiveram um bom rendimento quanto ao número de acertos das questões (Tabela 1).

Tabela 1 - Levantamento quantitativo das respostas dos alunos do $5^{\circ}$ e $9^{\circ}$ anos referente ao jogo educativo.

\begin{tabular}{|c|c|c|c|c|c|}
\hline $\begin{array}{c}\text { 1. Qual a média em } \\
\text { massa de água no corpo } \\
\text { humano? }\end{array}$ & $\begin{array}{c}5^{\circ} \\
\text { Ano }\end{array}$ & $\begin{array}{c}9^{\circ} \\
\text { Ano }\end{array}$ & $\begin{array}{l}\text { 4. São equipamentos } \\
\text { poupadores que ajudam na } \\
\text { economia de água: }\end{array}$ & $\begin{array}{c}5^{0} \\
\text { Ano }\end{array}$ & $\begin{array}{c}9^{\circ} \\
\text { Ano }\end{array}$ \\
\hline (a) $55 \%$ & 4 & 0 & $\begin{array}{l}\text { (a) Torneira de fechamento } \\
\text { automático }\end{array}$ & 13 & 11 \\
\hline (b) $65 \%$ & 1 & 0 & (b) Mangueira de jardim & 0 & 0 \\
\hline (c) $75 \%$ & 12 & 11 & $\begin{array}{l}\text { (c)Encanamentos com } \\
\text { vazamentos }\end{array}$ & 0 & 0 \\
\hline (d) $79 \%$ & 0 & 2 & (d) Regador e garrafa térmica & 4 & 2 \\
\hline $\begin{array}{l}\text { 2. Qual a necessidade de } \\
\text { água diária para o } \\
\text { consumo do corpo } \\
\text { humano? }\end{array}$ & & & 5. A água é um recurso: & & \\
\hline (a) $1,5 \mathrm{~L}$ & 3 & 0 & (a) Que deve ser desperdiçada & 2 & 0 \\
\hline (b) $5 \mathrm{~L}$ & 2 & 0 & (b) Limitado & 9 & 10 \\
\hline (c) $2 \mathrm{~L}$ & 12 & 13 & (c) Abundante & 2 & 2 \\
\hline (d) $1 \mathrm{~L}$ & 0 & 0 & (d) Ilimitado & 4 & 1 \\
\hline $\begin{array}{l}\text { 3. Em relação ao } \\
\text { desperdício de água, qual } \\
\text { a alternativa ERRADA? }\end{array}$ & & & $\begin{array}{c}\text { 6. O que causa a } \\
\text { CONTAMINAÇÃ̃ da } \\
\text { água? } \\
\end{array}$ & & \\
\hline $\begin{array}{l}\text { (a) Fechar a torneira ao } \\
\text { escovar os dentes }\end{array}$ & 0 & 0 & $\begin{array}{l}\text { (a) Substâncias que modificam } \\
\text { as características físicas e } \\
\text { químicas }\end{array}$ & 7 & 3 \\
\hline (b) Banhos de 20 minutos & 16 & 10 & $\begin{array}{l}\text { (b) Organismos benéficos à } \\
\text { saúde }\end{array}$ & 0 & 0 \\
\hline (c) Evitar vazamentos & 1 & 2 & $\begin{array}{l}\text { (c) Substâncias que não alteram } \\
\text { as características da água }\end{array}$ & 2 & 0 \\
\hline $\begin{array}{l}\text { (d) Lavar o carro com } \\
\text { balde }\end{array}$ & 0 & 1 & $\begin{array}{l}\text { (d) Organismos causadores } \\
\text { de doenças }\end{array}$ & 8 & 10 \\
\hline
\end{tabular}

*Alternativas indicadas em vermelho: representam as respostas corretas do jogo educativo aplicado. 


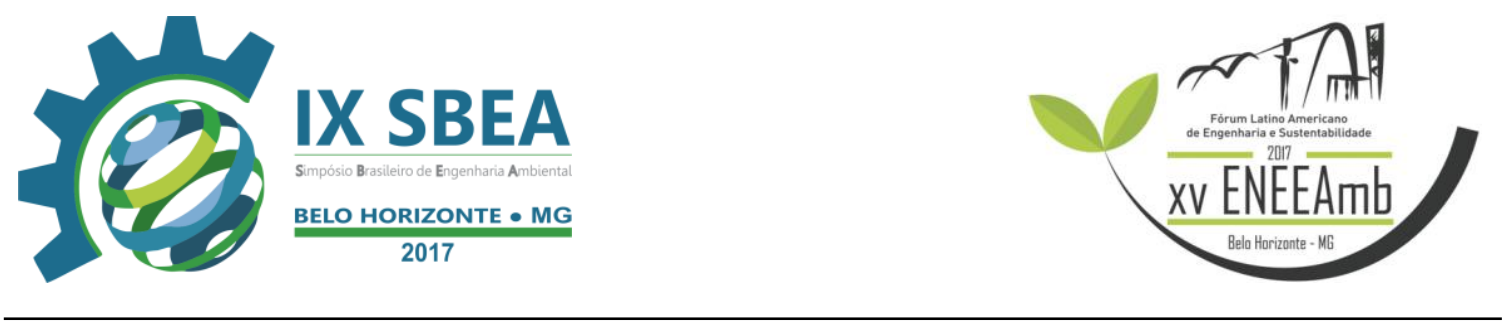

Na Questão 1, 71\% dos alunos do $5^{\circ}$ ano marcaram como resposta " $75 \%$ " de água, ou seja, os mesmos conseguiram aprender na explicação feita pelos educadores ambientais, o teor de água existente em várias partes do corpo humano. Já em relação aos alunos do $9^{\circ}$ ano, 92\% marcaram a resposta correta, ou seja, os mesmos conseguiram assimilar a explicação no início da aula. Na Questão 2, 70\% dos alunos do $5^{\circ}$ ano marcaram a alternativa correta " 2 Litros", visto que foi citado durante a aula e muitos alunos já continham esse conhecimento. Em contrapartida, $100 \%$ dos alunos do $9^{\circ}$ ano marcaram a alternativa correta. Na Questão 3, 94\% dos alunos do $5^{\circ}$ ano acharam ser incorreto tomar banhos de 20 minutos, ou seja, os mesmos possuem a consciência de que deixar o chuveiro ligado por 20 minutos é um tempo longo, o que provoca um gasto indevido da água. No entanto, notou-se que os alunos não estão sensibilizados com a causa, pois afirmaram que demoram no banho, mas que pretendiam mudar esse hábito. Em contrapartida, $77 \%$ dos alunos do $9^{\circ}$ ano acharam ser incorreto tomar banhos de 20 minutos, embora tenham o hábito de tomarem banhos demorados assim como os alunos do $5^{\circ}$ ano.

$\mathrm{Na}$ Questão 4, 76\% dos alunos do $5^{\circ}$ ano marcaram a alternativa correta, mas $24 \%$ dos alunos marcaram como sendo "Regador e garrafa térmica", e informaram que também é uma forma de poupar água, mas não observaram que havia duas respostas juntas, anulando a hipótese de que essa não seria a alternativa mais adequada. De forma parecida, $85 \%$ dos alunos do $9^{\circ}$ ano marcaram a alternativa correta, mas $15 \%$ dos alunos marcaram como sendo "Regador e garrafa térmica". Nesse sentido, os educadores ambientais acreditam que seria interessante fazer algumas adaptações na questão antes de aplicá-la em uma aula futura para evitar ambiguidades. Na Questão 5, a opção com maior número de marcações foi que a água é um recurso "limitado", mostrando que $56 \%$ do $5^{\circ}$ ano e $77 \%$ do $9^{\circ}$ ano compreenderam, com base na explicação dos educadores ambientais, que a água é um bem natural que pode se tornar escasso se o ser humano continuar provocando contaminações e usando indiscriminadamente este recurso.

Com os resultados da questão Questão 6, notou-se os educandos tiveram maior dificuldade, visto que apenas $47 \%$ da turma do $5^{\circ}$ ano conseguiu assimilar o conceito correto de contaminação e $41 \%$ trocaram a definição com a de poluição. Já em relação aos alunos do $9^{\circ}$ ano, $77 \%$ conseguiu entender o conceito correto em relação a 
contaminação da água e $23 \%$ trocaram a definição com a de poluição. Tal situação reforça que mesmo com os exemplos mostrados pelos educadores ambientais para a diferenciação de ambos os termos, alguns alunos ainda não associaram tais definições, sendo necessária a intervenção dos educadores ambientais com novos mecanismos de aprendizagem sobre os termos.

Na Questão dissertativa, 65\% dos alunos do $5^{\circ}$ ano disseram "sim" e justificaram que a possível falta desse recurso futuramente está relacionada ao desperdício e ações antrópicas. No entanto, 35\% dos alunos que disseram "não", pois se trata de um recurso presente no corpo humano e que, portanto, a sua falta levaria a morte de todos os seres vivos. Diferentemente do $5^{\circ}$ ano, $100 \%$ dos alunos do $9^{\circ}$ ano acreditam que a água pode acabar em função do desperdício provocado pelo próprio homem. Nota-se que a maioria dos alunos do $5^{\circ}$ ano possui uma visão de que a quantidade e a qualidade da água disponível para o consumo humano estão diminuindo, e os alunos do $9^{\circ}$ ano veem o homem como sendo um vilão à natureza.

Após o jogo educativo, foi desenvolvido o experimento prático sensorial das características da água (três amostras simuladas: água com terra, água com vinagre, e água limpa). O desempenho dos alunos foi semelhante nas duas turmas ( $5^{\circ}$ e $9^{\circ}$ anos), uma vez que todos os alunos disseram que a água escura (água com terra) não poderia ser consumida. Com relação às outras amostras, os alunos disseram que pelo aspecto visual poderia ser consumida. No entanto, quando sentiram o odor de uma das amostras (água com vinagre) fizeram caretas dizendo que não poderia ser consumida. Mediante tais relatos, os educadores ambientais explicaram que a água apresenta três características fundamentais (incolor, inodora e insípida) e que tais características reforçam que a água está livre de contaminação e/ou poluição.

Com o intuito de motivar os alunos, após a correção do jogo educativo, 5 alunos do $5^{\circ}$ ano e 4 alunos do $9^{\circ}$ ano que maior pontuaram foram premiados com uma lembrancinha para lembrar o esforço e atenção durante a aula.

\subsection{Questionário de satisfação das aulas ministradas}

Para avaliar a qualidade da aula ministrada, foi aplicado um questionário de satisfação contendo seis questões de múltipla escolha. Com base nos resultados do 


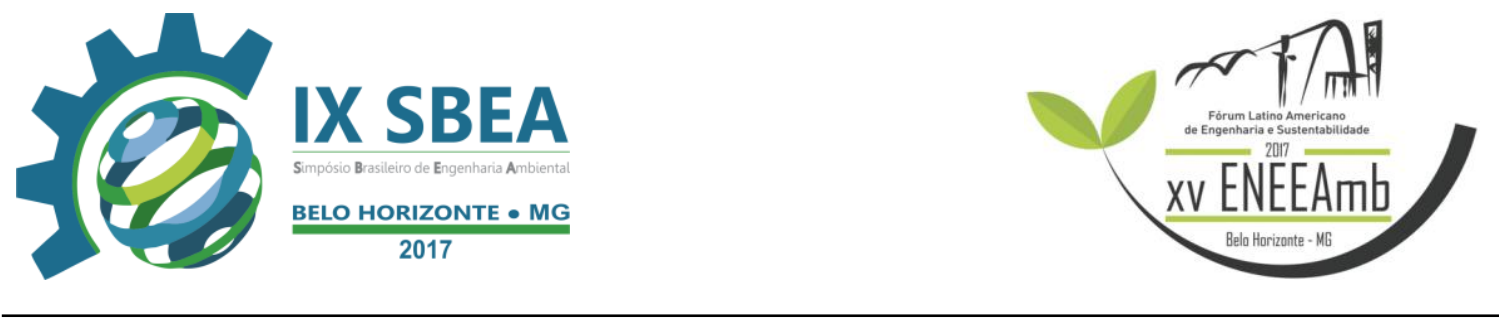

questionário apresentado na Figura 2, nota-se que a maioria dos alunos do $5^{\circ}$ Ano citou que gostaram mais do assunto "a importância da água", fato que pode estar relacionado à maior dinâmica que ocorreu no momento da explicação desse tópico. Foram realizados questionamentos e interação com os estudantes em relação ao significado de "água potável", assim como foram mostrados gráficos e imagens com exemplos de atividades industriais e domésticas, nas quais mais se utiliza a água, despertando a atenção e a curiosidade dos alunos.

Figura 2 - Exposição das respostas do questionário de satisfação aplicado aos estudantes do $5^{\circ}$ ano do Ensino Fundamental da Escola do Campo analisada.

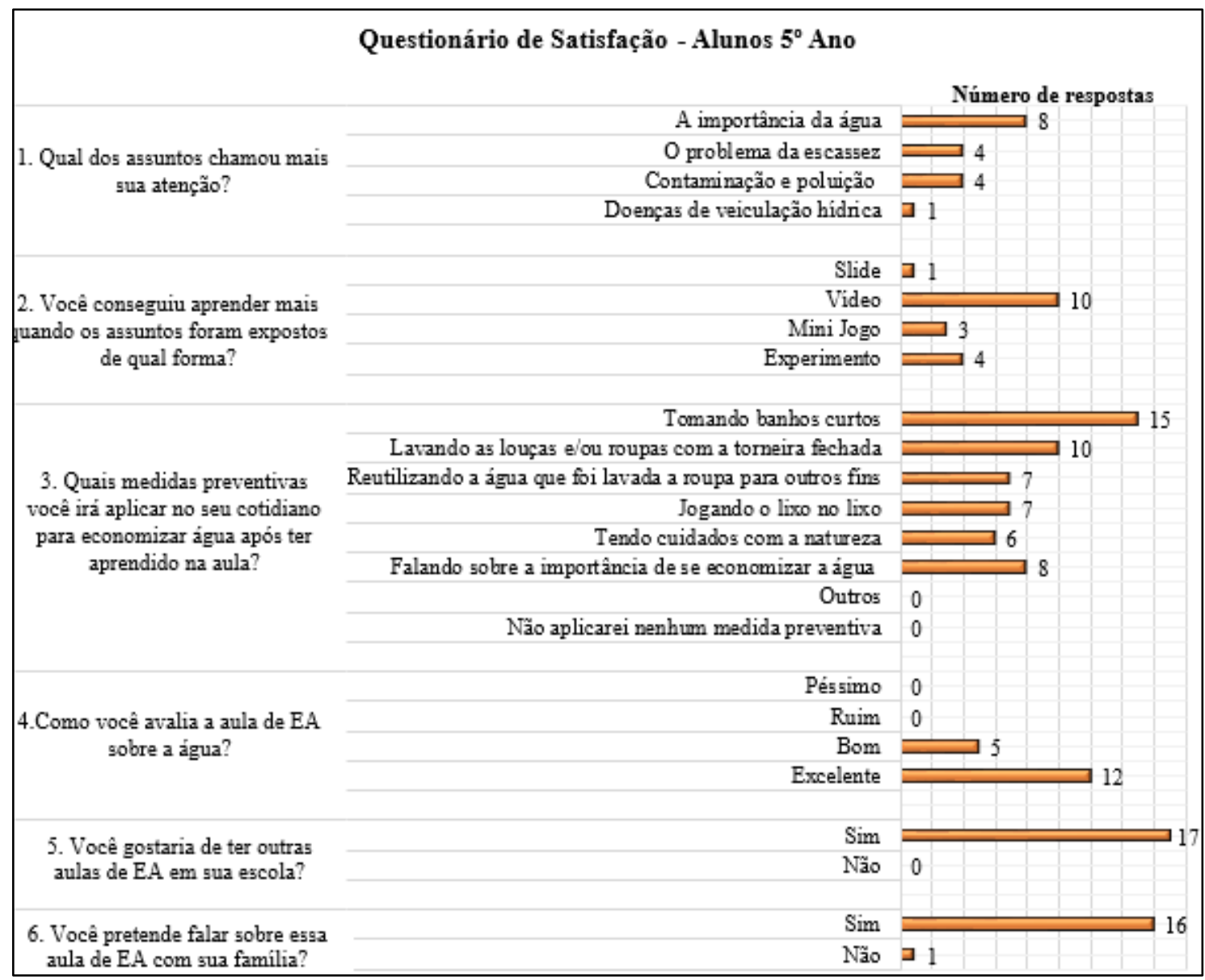

Já em relação aos resultados dos alunos do $9^{\circ}$ Ano, mostrados na Figura 3, do total de 13 alunos, ocorreu uma difusão em relação ao tema que foi mais interessante, visto que 5 alunos afirmaram ser "o problema da Escassez", 4 sobre "A importância da água" 


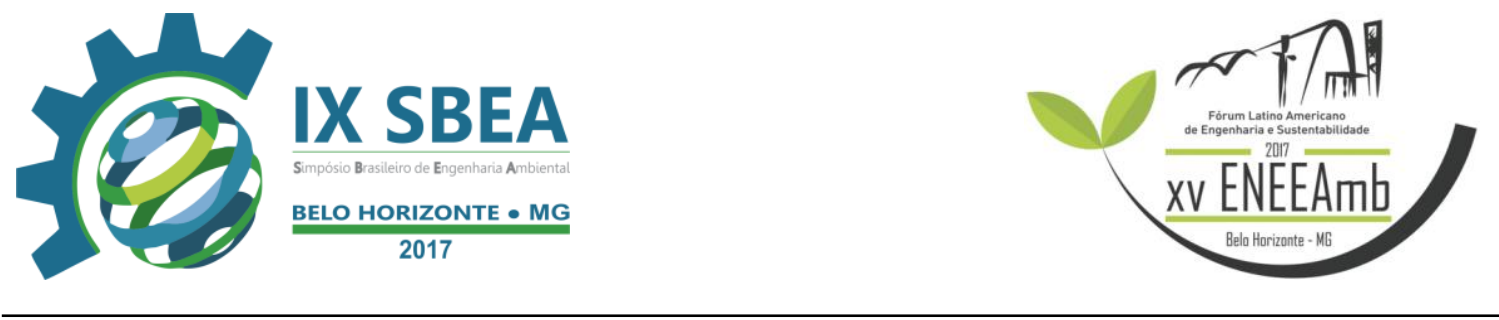

e 4 sobre "Contaminação e poluição". Provavelmente tal situação se explica pela forma de abordagem que foi utilizada durante a exposição e diálogo dos três temas, tendo em vista que foram utilizados recursos midiáticos impactantes e experimento prático motivador.

Figura 3 - Exposição das respostas do questionário de satisfação aplicado aos estudantes do $9^{\circ}$ ano do Ensino Fundamental da Escola do Campo analisada.

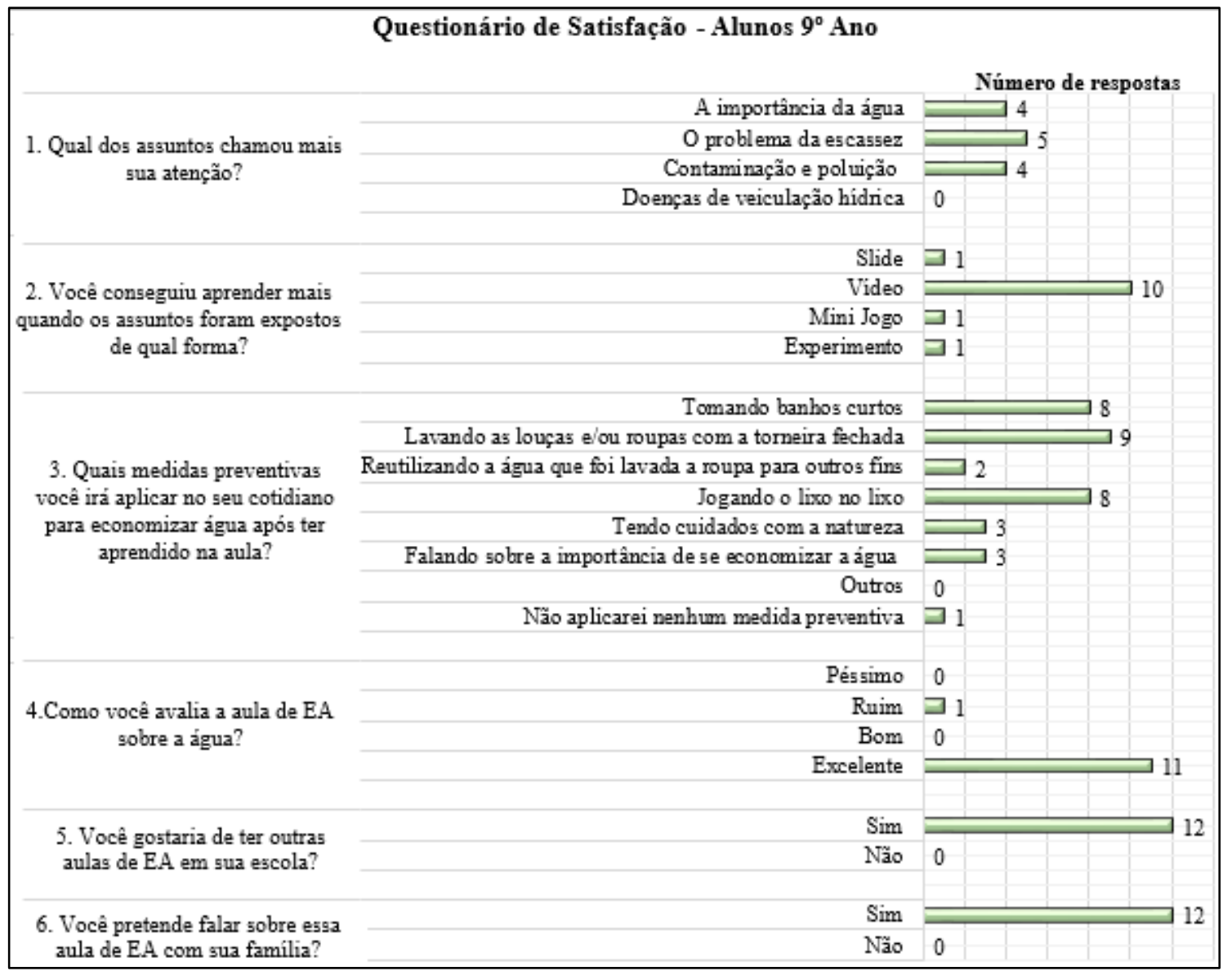

Em relação à forma de exposição dos assuntos, a maioria dos alunos do $5^{\circ}$ ano, assim como do $9^{\circ}$ ano, informou que a preferência foi do vídeo educativo. Esse resultado pode estar associado ao fato de que o ensino por meio de vídeos é um método moderno e chamativo, diferente das aulas tradicionais que esses alunos assistem cotidianamente. Sendo assim, o vídeo utilizado serviu para introduzir um novo assunto, possuindo uma boa sonoridade, forma ilustrativa e chamativa de informar sobre o uso racional da água, 


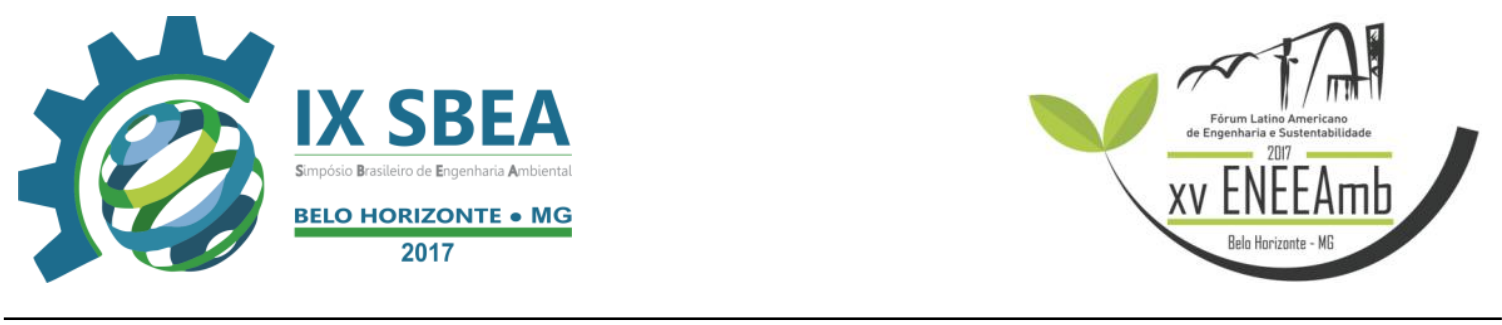

citando formas de adequadas de usar esse recurso para que o mesmo não venha a faltar. Além disso, possibilitou informar sobre equipamentos poupadores que ajudam a racionalizar o uso da água.

Quanto às formas preventivas para economia de água que os alunos pretendiam aplicar, estes poderiam marcar várias alternativas. Sendo assim, os alunos do $5^{\circ}$ ano sinalizaram que iriam reduzir o tempo do banho, visto que durante a aula, muitos alunos informaram que tomavam banhos longos. Já os alunos do $9^{\circ}$ ano, optaram, em sua maioria, por lavar louças e roupas com a torneira fechada, pois muitos disseram que não praticavam o hábito de fechar a torneira durante essas atividades. Ademais, nota-se que os alunos de $5^{\circ}$ ano optaram bastante pela medida de falar para sobre a importância da água com familiares e amigos, já para os alunos de $9^{\circ}$ ano essa medida foi pouco optada. Observa-se, portanto, que os alunos com idade menor possuem maior vontade de conversar sobre o tema, confirmando a necessidade de se trabalhar EA com alunos do ensino fundamental inicial.

Em relação à qualidade de exposição dos assuntos trabalhados, $71 \%$ da turma do $5^{\circ}$ ano avaliaram como sendo excelente e $100 \%$ afirmaram que gostariam de ter mais aulas de EA durante o ano escolar, reforçando ainda que $94 \%$ iriam conversar sobre a aula que eles tiveram com seus familiares. Notou-se que a satisfação dos alunos do $9^{\circ}$ ano também foi positiva, visto que $92 \%$ da turma avaliou a aula como sendo excelente, e $100 \%$ dos alunos informou que gostariam de mais aulas voltadas às questões ambientais e que pretendiam sim comentar com a família. Portanto, observa-se com os resultados que houve uma satisfação positiva das duas turmas.

\section{CONCLUSÕES/RECOMENDAÇÕES}

As estratégias pedagógicas aqui adotadas ressaltaram a conscientização dos alunos quanto à contaminação, uso inapropriado da água nas atividades cotidianas e industriais e ainda buscou verificar a satisfação dos alunos em relação às estratégicas pedagógicas utilizadas. Dentre as duas turmas analisadas, a que possuiu debate mais aprofundado foi o $5^{\circ}$ ano, visto que se mostraram participativos e curiosos durante as atividades, mesmo apresentando dificuldades nos assuntos “escassez”, e na diferenciação dos conceitos "poluição" e "contaminação". Logo, acredita-se que em aulas futuras, os 


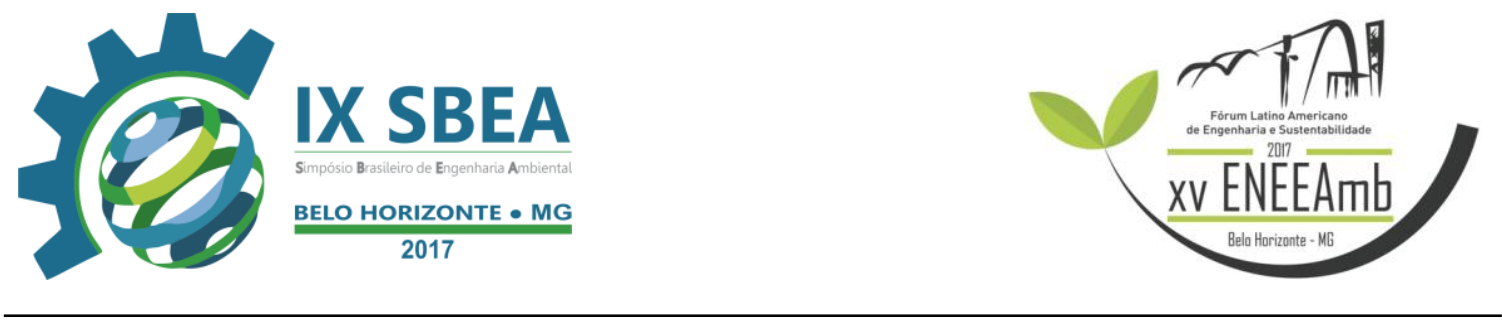

educadores ambientais devam abordar atividades com maior enfoque para esses termos. Já os alunos do $9^{\circ}$ ano se mostraram pouco empolgados e interessados nos assuntos no início da aula, uma vez que já detinham conhecimentos prévios mais sólidos em relação ao tema. Portanto, acredita-se que a elaboração de aulas mais atrativas e com informações inovadoras irão agregar maior conhecimento a turma.

Com base nos resultados do questionário de satisfação, ambas as turmas opinaram que a melhor estratégia pedagógica foi a transmissão do vídeo educativo sobre o uso racional de água, reforçando que recursos multimídia podem ser interessantes para aprendizagem de conteúdos científicos. Portanto, a aplicação do questionário se constituiu em uma importante ferramenta de avaliação das aulas aplicadas, uma vez que gerou subsídios aos educadores ambientais para elaboração de aulas futuras que priorizam os aspectos que chamaram maior atenção dos alunos.

\section{AGRADECIMENTOS}

Os autores agradecem aos órgãos de fomento FAPEMIG (processos números: APQ- 02249-14 e APQ-03219-14), CNPq, Rede Mineira pelos auxílios financeiros e bolsas concedidas (APQ-03219-14).

\section{REFERÊNCIAS BIBLIOGRÁFICAS}

FERREIRA, M. V. M. Avaliação de projetos de educação ambiental na lagoa da Pampulha (MG). Revbea, v. 10, n. 01, p. 164-179, 2015.

FREITAS, N. T. A.; MARIN, F. A. D. G. Educação ambiental e água: concepções e práticas educativas em escolas municipais. Nuances: estudos sobre Educação, v. 26, número especial 1, p. 234-253, 2015.

MASSABNI, V. G. et al. Sustentabilidade na educação infantil: ciclo, aproveitamento e uso consciente da água. Revista Eletrônica Sala de Aula em Foco, v. 04, n. 01, p. 47$57,2015$.

WESENDONK, F. S.; PRADO, L. Atividade didática baseada em experimento: discutindo a implementação de uma proposta investigativa para o ensino de física. Experiências em Ensino de Ciências, v. 10, n. 01, p. 54-80, 2015. 